\title{
Anti-hyperglycaemic properties of cinnamon depends on the species
}

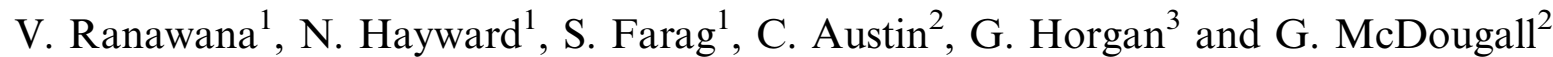 \\ ${ }^{1}$ Rowett Institute, University of Aberdeen, Aberdeen AB25 2ZD, ${ }^{2}$ James Hutton Institute, Invergowrie, Dundee DD2 \\ $5 D A$ and ${ }^{3}$ Biomathematics \& Statistics Scotland, Aberdeen, AB25 $2 Z D$.
}

Cinnamon has been reported to have anti-diabetic properties, however prevailing evidence is equivocal and precludes firm conclusions ${ }^{(1)}$. The ambiguity of reported findings may be due to the use of different cinnamon species in studies, an aspect that has received little research attention. The aim of the current study was to compare the anti-hyperglycaemic properties of the four principal Cinnamon species used round the world i.e. Chinese (C. cassia $[\mathrm{CC}])$, Indonesian C. burmanii [IC]), Vietnamese (C. loureirii $[\mathrm{VC}])$ and Ceylon (C. zeylanicum $[\mathrm{SC}]$ ) cinnamon.

Water extracts of cinnamon were prepared from bark powders ${ }^{(2)}$, and characterised for polyphenol content, antioxidant potential ${ }^{(3)}$, and effects on $\alpha$-amylase (AA) and $\alpha$-glucosidase (AG) enzyme inhibition ${ }^{(4)}$. The impact of the extracts on starch digestion was assessed using a standardised in vitro gastro-intestinal digestion model ${ }^{(5)}$, using white bread as the test substrate.

All cinnamon types showed high antioxidant and polyphenol contents, with CC and IC showing the greatest values $(\mathrm{p}<0.001)($ Fig. 1). Chinese C, IC and VC showed the best effects on AA inhibition ( $p<0.001)$. All species showed potent effects against AG compared to acarbose, particularly CC and IC $(\mathrm{p}<0.001)$. Chinese $\mathrm{C}$, IC and SC reduced glucose release from bread during the oral and gastric phases of digestion compared to the control, $(\mathrm{p}<0.05)$, but were similar to each other $(\mathrm{p}>0.05)$. The best overall effects during digestion was seen with SC (Table 1). The cinnamon extracts did not affect the contents of rapidly digestible, slowly digestive or resistant starches.

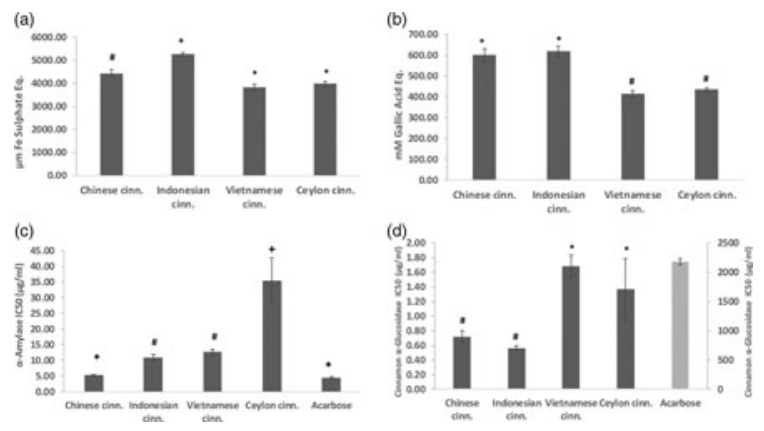

Fig. 1. Antioxidant potential (A), Total polyphenols (B), $\alpha$-Amylase activity inhibition (C), and $\alpha$-Glucosidase activity inhibition (D) for the four cinnamon types. Enzyme inhibition potency increases with smaller IC50 values. Columns with different symbols are significantly different, one-way ANOVA followed by Tukey's test, $\mathrm{p}<0.05$. Error bars are standard deviations $(\mathrm{n}=3)$. Data represents samples obtained from a single bulk extraction.

Table 1. Effect of $\mathrm{CC}, \mathrm{IC}, \mathrm{VC}$ and $\mathrm{SC}$ on starch hydrolysis during simulated digestion of white bread. RDS: Rapidly Digestible Starch, SDS: Slowly Digestible Starch and RS: Resistant Starch. $=:$ Not Significantly different to control; $\checkmark$ : Significantly different to control. One-way ANOVA with Tukey test, $\mathrm{p}<0.05, \mathrm{n}=3$.

\begin{tabular}{|c|c|c|c|c|c|c|c|c|c|}
\hline & \multicolumn{6}{|c|}{ Glucose release during in vitro digestion } & \multirow{3}{*}{ RDS } & \multirow{3}{*}{ SDS } & \multirow{3}{*}{ RS } \\
\hline & \multirow[b]{2}{*}{ Baseline } & \multirow[b]{2}{*}{ Oral phase } & \multirow[b]{2}{*}{ Gastric phase } & \multicolumn{3}{|c|}{$\begin{array}{l}\text { Intestinal } \\
\text { phase (min) }\end{array}$} & & & \\
\hline & & & & 60 & 120 & 180 & & & \\
\hline $\mathrm{CC}$ & $=$ & $\checkmark$ & $=$ & $=$ & $=$ & $=$ & $=$ & $=$ & $=$ \\
\hline IC & $=$ & $\checkmark$ & $\checkmark$ & $=$ & $=$ & $=$ & $=$ & $=$ & $=$ \\
\hline $\mathrm{VC}$ & $=$ & $=$ & $=$ & $=$ & $=$ & $=$ & $=$ & $=$ & $=$ \\
\hline $\mathrm{SC}$ & $=$ & $\checkmark$ & $\checkmark$ & $=$ & $\checkmark$ & $=$ & $=$ & $=$ & $=$ \\
\hline
\end{tabular}

In conclusion, water extracts of cinnamon demonstrate anti-hyperglycaemic properties that are species-specific. Of the four studied, $\mathrm{CC}$, IC and SC showed greater potential.

1. Yilmaz Z, Piracha F, Anderson L, Mazzola N (2017) Journal of Pharmacy Practice;30(6):631-8.

2. Cheng DM, Kuhn P, Poulev A, Rojo LE, Lila MA, Raskin I (2012) Food Chem;135(4):2994-3002.

3. Raikos V, McDonagh A, Ranawana V, Duthie G (2016) Food Science and Human Wellness; 5(4):191-8.

4. Pantidos N, Boath A, Lund V, Conner S, McDougall GJ (2014) J. Functional Foods; 10:201-9.

5. Minekus M, Alminger M, Alvito P, Ballance S, Bohn T, et al. (2014) Food \& Function; 5:1113-24. 